\title{
Demography and Uncertainty in Economic Growth: An Application to Social Security
}

\author{
Miguel Sánchez Romero* \\ Universidad Autónoma de Madrid \\ miguel.romero@uam.es
}

\begin{abstract}
The aim of this paper is to study the impact on economic growth of public pension systems, both funded and unfunded, under different demographic scenarios with a competitive economy and a fixed labor supply. An OLG growth model is used with realistic demography, in which each individual can be traced throughout her lifecycle, by using a longitudinal accounting framework. Under this setup, I find that both funded and unfunded pension systems can achieve the same steady state, either the «modified golden rule» or the «golden rule,» as long as the population increases. Nonetheless, the dynamic transition of each social security system to this steady state differs. This result shows that when labor supply is inelastic public pension systems do not necessarily alter the capital stock in the long run.

* I am thankful to Felipe Sáez, Juan Carlos Conesa, Joaquín Vera Grijalba, Fernando García-Belenguer Campos, and two anonymous referees for their helpful suggestions and comments. Aid from the Universidad Autónoma de Madrid during the last four years is also gratefully acknowledged. Any errors are my own.
\end{abstract}


Keywords: Overlapping generations, Demography, Multiple equilibria, Social Security, Crowding-out effect

JEL classification: D9, E13, E27, H55, O40

\section{INTRODUCCIÓN}

In this article I propose to study how social security systems, either funded or unfunded, affect the capital stock, and thus economic growth. This issue was first approached by Feldstein (1974). Using a time-series study, he pointed out that the U.S. pay-as-you-go social security system «had substantially decreased aggregate capital accumulation». His claim was based on the fact that the introduction of the pension system reduced the labor supply through early retirement and, as a consequence, reduced future savings. This result was later supported by Boskin and Hurd (1978), who empirically showed that for the U.S. the unfunded system distorts the labor supply by inducing people to retire earlier. Theoretic models, however, state that in order to obtain the above results either the rate of return between private savings and public pension must differ, or must exist market imperfections such as liquidity constraints. It might be thus expected that if any of the above conditions were satisfied funded pension systems would cause effects on the capital stock similar to those of unfunded systems.

Additionally, the negative impact of unfunded social security is far from being widely accepted, since such results rely on restrictive assumptions about, among others the behavior of the economic agent, the population structure, and even market features. The main advantage of this lack of consensus is the increase in research on the effect of social security on the economy. For example, Auerbach and Kotlikoff (1987) used simulations to show that an unfunded social security, introduced into an economy composed of selfish individuals, crowds out the stock of physical capital. However, the crowding-out effect is reduced or eliminated when individuals have altruistic feelings, Fuster et al. (2003) and Fuster (1999). Also, there exists a crowding out when an actuarially fair social security is introduced into an economy with market failures in the provision of private annuities, Hubbard (1987) and Abel (1985). In sum, to fully comprehend this issue, one must understand how each social security system affects each variable separately, as many counter-effects exist that might address flawed policies.

Thus, this paper develops an OLG growth model with realistic demography, which enables us to track each individual throughout her life cycle. In contrast to Feldstein (1974) and Boskin and Hurd (1978), I assume that the labor supply is fixed 
and that social security systems are actuarially fair. This assumption is introduced for two reasons. First, it helps to separate the impact of the social security in the capital stock from the distortion upon capital caused by changes on labor supply. Second, it can then be assumed that neither funded nor unfunded pension systems induce workers to modify their optimal age of retirement, which simplifies our model ${ }^{1}$. Thus, we extend the Cass-Koopmans-Ramsey model ${ }^{2}$ by introducing a longitudinal accounting framework, instead of adopting the cross-sectional accounting. This approach to the problem has been already attempted by Bommier and Lee $(2003)^{3}$. Nonetheless, my model differs from Bommier and Lee (2003) in two aspects. First, we present a longitudinal accounting framework that more easily allows economic interpretation. This is partly because we do not need to differentiate with respect to time and age. Second, this model is based on the Cass-Koopmans-Ramsey model instead of the Gale (1973) model. Other related papers, such as Calvo and Obstfeld (1988) and Blanchard (1985), have considered a dynamic continuous model with lifetime uncertainty as well. However, their models do not have a longitudinal accounting.

The results of this paper show that a realistic demography, coupled with the longitudinal accounting framework, modifies the usual dynamic function of consumption per capita. Thus, in general, there will exist three kinds of steady states: i) the golden rule in which the interest rate equals the population growth rate as in Phelps (1966), ii) the modified golden-rule in which the interest rate equals the subjective discount factor plus a proportion of the population growth rate, and iii) a non-trivial steady state that depends on both economic and demographic variables. I also find that both funded and unfunded social security systems achieve the golden rule and the modified golden-rule. Therefore, contrary to what previous research has shown, an unfunded social security has no effect on saving rates and capital accumulation in the long run. However, the unfunded system causes a temporal intergenerational

${ }^{1}$ Nonetheless, we do not need to assume that labor supply is fixed if the economy is in the golden rule equilibrium, because the rate of return of both private savings and pension systems are the same.

${ }^{2}$ Ramsey (1928), Cass (1965), and Koopmans (1965) analyze the evolution of the consumption and the stock of physical capital through the interaction between competitive firms and maximizing consumers. The main feature of these models is that the saving rate is an endogenous variable.

${ }^{3}$ This paper presents an excellent overview about the evolution of the use of demography in economic models. 
problem before it reaches the steady state. During this transition, there seems to be a crowding-out effect on the stock of physical capital.

The model has five features. First, the economy is closed to both migration and investments from other economies. Second, there exists a productive firm that combines labor and physical capital to produce a storable good, which can be either consumed or saved by each individual. Third, the population is composed of selfish people who face an uncertain length of life. Therefore, there are no intergenerational transfers. Fourth, each individual supplies her labor inelastically up to the age of retirement. The implications of this fact are twofold. The population must be divided into workers and retirees and precautionary motive causes people to save. Fifth, a selfish individual will prefer, according to Yaari (1965), to purchase annuities; thus we assume that there exists a pooling of risk that offers actuarially fair private annuities.

The remainder of this paper proceeds as follows: Section 2 presents the longitudinal accounting framework applied to our population. I show how both cross-sectional and longitudinal frameworks are similar at any time. Some useful demographic functions and how they evolve over time will be also explained. Section 3 is devoted to developing the longitudinal accounting framework for the economic variables. The main aggregate and per capita functions, as well as their dynamic motion equations, are presented. Section 4 introduces the economic framework and analyzes the main results for an economy without social security. The impact of social security on economic growth is introduced in Section 5. This section is divided into two subsections in order to study the effects of both funded and unfunded systems on the economy. Section 6 concludes. Finally, an Appendix containing the main proofs completes the paper.

\section{Demographic Accounting Framework}

A growth economic model with realistic demography is based on the structure of its population and its size over time. As a first step, I will set up the demographic back-ground. Henceforth, I assume a «closed population» (no migration flows), which only changes through births $B$ and deaths $D$. Thus, the population growth rate at time $t$, denoted as $n(t)$, corresponds to the crude birth rate minus the flow of deaths per capita at time $t, b(t)-d(t)$. Let us call those people who were born at year $x$ «cohort $x$.» The size of the cohort $x$ at age $s$ will be given as $\Omega_{x}(s) B(x)$, where $\Omega_{x}(s)$ is the probability that an individual who was born in year $x$ will be alive at age $s$ (see Definition 1 in the Appendix). Therefore, the size of our population at time $t$, denoted by $P(t)$, is found by adding up the size of every cohort alive at that time. 
There are two different ways of calculating $P(t)$, either in a cross-sectional perspective or in a longitudinal perspective:

$$
P(t)=\underbrace{\int_{0}^{T} \Omega_{t-s}(s) B(t-s) d s}_{\text {Cross-Sectional }}=\underbrace{\int_{t-T}^{t} \Omega_{x}(t-x) B(x) d x,}_{\text {Longitudinal }}
$$

where $T$ is maximum age, or longevity, of any individual. In this paper, I use the longitudinal accounting, rather than cross-sectional accounting, because of the following reasons. With longitudinal accounting, I do not need to differentiate with respect to time and age in order to derive the evolution of any socio-economic variable over time. I only need to differentiate with respect to time. Also, the longitudinal accounting enables one simultaneously analyze the behavior of an individual both at age $s$ and over her life cycle. Given this accounting framework, I will thus begin evaluating each scenario by analyzing the individual life-cycle behavior, and then obtaining the aggregate results.

Equation (1) is useful for aggregate functions, however for the sake of consistency with respect to previous growth models, I am also interested in per capita variables. The size per capita of the cohort $x$ at time $t$ is defined as $p_{x}(t-x)$ :

$$
p_{x}(t-x)=\frac{\Omega_{x}(t-x) B(x)}{P(t)}=\frac{\Omega_{x}(t-x) B(x)}{\int_{t-T}^{t} \Omega_{\tau}(t-\tau) B(\tau) d \tau}
$$

Equation (2) evolves over time according to the following law of motion:

$$
\dot{p}_{x}(t-x)=-\left(\mu_{x}(t-x)+n(t)\right) p_{x}(t-x), \text { with } t \geq x
$$

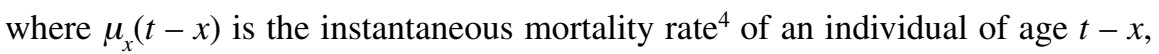
born at year $x$. In addition to equation (2), let us call $\tilde{p}(t-x)$ as the stable cohort $x$ per capita at time $t$. From (3), $\tilde{p}(t-x)$ has the following expression:

${ }^{4} \mu$ is also called by demographers as «mortality hazard rate» and by actuaries as «force of mortality». 


$$
\tilde{p}(t-x)=\Omega(t-x) b e^{-n(t-x)}, \quad t \geq x .
$$

Previous models, such as Blanchard $(1985)^{5}$, assume that the population is stationary $(n(t)=0, \forall t)$ and that the instantaneous mortality rate is constant along the lifespan. Instead, following the lead of Bommier and Lee (2003), I will consider a realistic mortality rate, since it improves the theoretical results and does not introduce too much complexity into the model. Nonetheless, our main findings will be presented under a «stable population» structure. That is, the population grows at a rate equal to $n$, and thus the size of any cohort per capita will remain constant over time.

Figure 1. Stable Population Structures

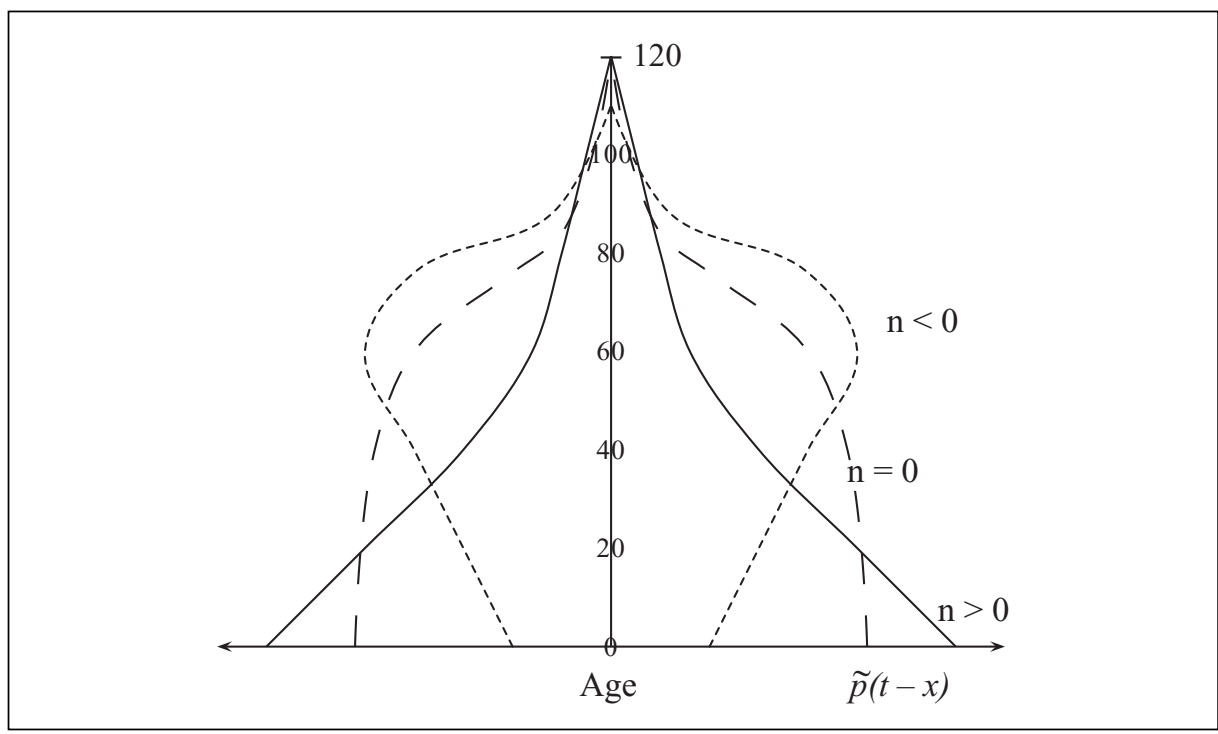

${ }^{5}$ An individual with a constant instantaneous mortality rate has the same life expectancy at any age. According to this fact, her marginal propensity to consume will be constant over time. 
Figure 1 above shows three hypothetical distributions of stable cohorts per capita according to age and population growth rate. Note that we only need to change the value of $n$ in order to obtain a young age pyramid ( $n>0$, solid line) or an aging age pyramid $(n<0$, dotted line).

\section{Aggregate and Per Capita Functions}

I will now develop an accounting framework for describing any aggregate variable, any per capita variable, and an individual counterpart at time $t$, in which any realistic demography could be considered. In addition, I will also calculate how the previous variables evolve over time in order to determine its steady states.

I indicate aggregate variables by uppercase letters $Z$, a per capita variables by lowercase letters $z$, and an individual's variable by lowercase letter followed by a subscript $z_{x}^{6}$.The relation between an aggregate variable and individual counterpart is

$$
Z(t)=\int_{t-T}^{t} z_{x}(t-x) \Omega_{x}(t-x) B(x) d x .
$$

Equation (5) shows that the aggregate value of any variable corresponds to the sum of the cohort's average values of that variable times the number of people within the cohort. For example, aggregate consumption is the sum of the average consumption of each cohort, multiplied by the number of people within the cohort. Similarly, we can use equation (2) to find the formula for the per capita variable:

$$
z(t)=\frac{Z(t)}{P(t)}=\int_{t-T}^{t} z_{x}(t-x) p_{x}(t-x) d x .
$$

\footnotetext{
${ }^{6}$ The subscript denotes the year in which the individual was born.
} 
The interpretation of equation (6) is simple. $z$ is the average value of $Z$ for our population at time $t$.

So far, I have shown our variable $z$ only in a specific moment. We are now interested in knowing how equations (5) and (6) evolve. So, I will differentiate both equations with respect to time, which gives

$$
\begin{aligned}
\dot{z}(t)= & \int_{t-T}^{t} \dot{z}_{x}(t-x) p_{x}(t-x) d x-n(t) z(t)+ \\
& b(t) z_{t}(0)-\int_{t-T}^{t} \mu_{x}(t-x) z_{x}(t-x) p_{x}(t-x) d x,
\end{aligned}
$$

and

$$
\dot{Z}(t)=P(t)(\dot{z}(t)+n(t) z(t))
$$

To understand (7), I divide it into three terms. The first integral represents how $z$ evolves for each current cohort. The second term represents how $z$ decreases through dilution due to population growth and the third term depicts how $z$ may change because of the increment produced by newborns and the reduction caused by deaths. With the exception of Bommier and Lee (2003), this third part has not been taken into account before. However, it is crucial for the analysis of growth models with overlapping generations, since young and old people do not necessarily allocate the same amount of their resources for a given variable $z$, as is generally considered. For example, based on (7), previous models are implicitly assuming that the consumption of newborns, $b(t) c_{t}(0)$, equals the consumption of those people who have just died. That is,

$$
b(t) c_{t}(0)=\int_{t-T}^{t} \mu_{x}(t-x) c_{x}(t-x) p_{x}(t-x) d x .
$$

In order to better understand this inconsistency, we can imagine a stationary population structure. Under this demographic scenario, this equality only holds whenever the consumption of older people is the same as that of young people. Meanwhile, under an aging population, it holds only if older people consume less than young people. In sum, we can conclude that this second equality is not realistic according to theoretical age consumption profiles.

On the other hand, equation (8) suggests that, despite the fact that population 
growth diminishes per capita variables, aggregate variables are positively affected by population growth.

\section{Economic Framework}

In a closed economy, there is only one firm that combines labor $L$ and physical capital $K$ to produce a single commodity or output, as a whole $F$. For simplicity, I assume that $F$ is an homogeneous function of degree one, and that there is no technological progress. Thus, the production function takes the following modified intensive form

$$
F(t)=P(t) f(k(t), l(t)) \equiv P(t) f(t)
$$

where $k(t)=\frac{K(t)}{P(t)}$ is the physical capital per capita at time $t$, and $l(t)=\frac{L(t)}{P(t)}$ is the ratio of workers to population at time $t$. Lastly, $f$ satisfies the conditions, $f \geq 0, f_{k}, f_{l} \geq 0$, $f_{k k^{\prime}}, f_{l l} \leq 0$, and $f_{k l}=f_{l k} \geq 0$, as well as the Inada conditions.

It is assumed that each individual supplies her labor force inelastically up to the age of $J$ years old, in exchange for a salary $w$ that corresponds to the marginal productivity of labor,

$$
w(t)=f_{l}(k(t), l(t))
$$

Afterwards, she decides to retire. Hence, the population at time $t$ can be divided into workers $L(t)$ and retirees $L^{r}(t)$

$$
P(t)=L(t)+L^{r}(t)=\underbrace{\int_{t-J}^{t} \Omega_{x}(t-x) B(x) d x}_{\text {Workers }}+\underbrace{\int_{t-T}^{t-J} \Omega_{x}(t-x) B(x) d x}_{\text {Retirees }} .
$$

It is worth noting that by introducing retirees, the retirement motive will encourage savings. Furthermore, this assumption gives insight into the consequences of a population with a longer life expectancy for the economy. Therefore, it helps to determine the optimal retirement age, and even to study feasible policies for balancing this unfavorable effect with the social security system. 
Individuals are assumed to have perfect foresight and to not have a bequest motive (selfish), so they only receive satisfaction through consumption $c$. In addition to these facts and with the intention of maximizing their utility, individuals constitute a pool for insuring their risk of mortality. Therefore, they purchase actuarially fair annuities in order to not outlive their resources in the case of survival beyond their life expectancy.

This annuity contract has two important features. First, after paying the premium, and if the individual survives at the end of the annuity contract, she will receive the marginal productivity of the physical capital, or the safe interest rate $r$,

$$
r(t)=f_{k}(k(t), l(t))
$$

plus a risk premium $\mu$ contingent on her mortality risk. However, if she does not survive at the end of the annuity contract, she will lose her premium. Second, the purchase of annuities leads to newborns not receiving bequests. As a consequence, individuals start their life-cycle without physical capital. According to Yaari (1965), each individual belonging to any cohort $x$ can be economically characterized by the following dynamic budget constraint:

$$
\dot{k}_{x}(t-x)=\left(r(t)+\mu_{x}(t-x)\right) k_{x}(t-x)+w_{x}(t-x)-c_{x}(t-x)
$$

where

$$
w_{x}(t-x)=\left\{\begin{array}{clc}
w(t) & \text { if } & 0<t-x<J \\
0 & \text { if } & t-x \geq J
\end{array}\right.
$$

and

$$
k_{x}(0)=0
$$

This dynamic budget constraint shows two key features. First, the greater physical capital rate of return is due to the fact that the individual purchases annuities. In particular, $\mu_{x}(t-x) k_{x}(t-x)$ corresponds to the proportion of wealth transferred from people within the cohort $x$ who are recently deceased. Second, by aggregating every individual within the economy, we are able to see that lifetime uncertainty does not affect the capital stock $K$ in the short run. However, it does affect the future stock of physical capital in the long run through consumption. Consequently, how consumption evolves over time must also be studied. 
If an individual's preferences can be represented by a CRRA utility function and every individual maximizes their lifetime utility, then the dynamic of consumption will be

$$
\dot{c}_{x}(t-x)=\frac{r(t)-\delta}{\gamma} c_{x}(t-x) \text { for all } t \geq x,
$$

where $\gamma>0$ is the constant risk aversion coefficient, and $\delta$ is the subjective discount parameter. Equation (14), known as the Euler Equation, implies that any individual of the cohort $x$ will consume more (respectively less) at some date $t+d t$ whenever the market interest rate is greater (respectively lower) than her subjective discount factor ${ }^{7}$. Accordingly, as long as $r(t) \geq \delta$, we can expect that every present and future cohort will have a non decreasing consumption throughout her life-cycle.

\subsection{The Dynamics of the Economy}

Thus far we have established the optimal individual behavior of any person within a cohort $x$, when she purchases actuarially fair private annuities and there is no social security system. Now I will use the longitudinal accounting framework to describe the evolution of this economy in terms of per capita variables: consumption per capita $c(t)$ and physical capital per capita $k(t)$ at any time $t$.

The aim is to derive the stationary state, or stationary states, of this economy. To do so, I proceed by first deriving how physical capital and consumption evolve. Second, I will calculate the singular or multiple steady states of the economy.

I will begin by deriving the dynamic of physical capital per capita. Thus, I combine equation (7) with the optimal consumer's allocation process described by equations (11), (13), and (14). As a result, the dynamic of physical capital per capita at time $t$ is

$$
\dot{k}(t)=f(t)-c(t)-n(t) k(t)
$$

${ }^{7}$ Equation (14) holds at $t+d t$ if, and only if, we assume that individuals have perfect foresight about their future earnings. 
This physical capital dynamic is the same as that in Solow (1956), Blanchard (1985), Bommier and Lee (2003), among many others. Annuities transfer the wealth from deceased individuals to those individuals who are alive at the end of the annuity contract.

As in previous analyses, the latter equation also implies that in the steady state, or steady states, consumption per capita should be equal to

$$
c=f-n k=(r-n) k+w l .
$$

As a consequence, by using equation (8), both aggregate physical capital and aggregate consumption will grow in a stationary state at a constant rate equal to $n$, independently of both the number of workers and the stock of physical capital per capita accumulated. That is,

$$
\frac{\dot{K}}{K}=n=\frac{\dot{C}}{C}
$$

These previous results are all well-known. However, the problem arises when we study the dynamic of consumption per capita. Contrary to the variable physical capital per capita, I do not expect the consumption of those people who are born at time $t, c_{t}(0) b(t)$, equals the consumption of people recently deceased, $\phi_{c}(t) c(t)$. In fact, their consumption can be either greater, or equal, or less than that of the newborns ${ }^{8}$. By introducing (14) into (7), the dynamic of consumption per capita is

$$
\dot{c}(t)=\left(\frac{r(t)-\delta}{\gamma} n(t)\right) c(t)+c_{t}(0) b(t)-\phi_{c}(t) c(t),
$$

where $\phi_{c}(t) c(t)$ is equal to

${ }^{8}$ That this result is different from that of the variable physical capital mainly stems from the fact that consumption is not a stock variable. 


$$
\int_{t-T}^{t} \mu_{x}(t-x) c_{x}(t-x) p_{x}(t-x) d x .
$$

Equation (17) shows that the dynamic of consumption per capita is not well estimated unless we subtract the consumption of people recently deceased at the same time as we add the newborns' consumption. Unfortunately, because variables $c_{t}(0)$ and $c_{x}(t-x)$ depend on the interest rate $r(t)$, the stationary consumption per capita $(\dot{c}=0)$ is very difficult to obtain, perhaps even impossible, for a non-stable population. Consequently, I will henceforth assume that our population is stable. On the other hand, in steady states the dependence on $t$ disappears. Thus, I can use the cross-sectional accounting, rather than the longitudinal accounting, to derive the steady state. The next theorem gives the necessary conditions for a stationary economy under the cross-sectional accounting framework.

Theorem 1. Let assume a closed population that faces an uncertain length of life and grows at a constant rate equal to $n$. If private markets offer actuarially fair annuities, then consumption per capita and physical capital per capita will be stationary for any interest rate that satisfies either:

$$
r=\delta+\gamma n
$$

or

$$
(r-n) k+w l=c(0) \int_{0}^{T} \mathrm{e}^{\frac{r-\underline{\delta}_{s}}{\gamma}} \tilde{p}(s) d s .
$$

\section{Proof. See Appendix.}

Theorem 1 claims that, given a constant population growth rate, there can be more than one feasible steady states in the economy. I find that one of the multiple steady states corresponds to the consumption and physical capital per capita in which $r$ is equal to $\delta+\gamma n$. This steady state is known as «the modified golden rule.» I also find that whenever the equation (19), is satisfied, the modified golden rule is not the only steady state that this economy can reach. In fact, according to (19) there can be two additional steady states. One is a non-trivial steady state that not only depends on socio-demographic variables $\{J, T, \Omega, b$, and $d\}$, but also on economic variables $\{r$, 
$w, \gamma$ and $\delta$ (see point III in Figure 2). The other is a steady state that corresponds to the «golden rule» condition, where $r=n$ or point $\mathrm{I}$ in Figure 2.

The number of steady states in an annuitized economy depends on the population growth rate. While a growing population (see Figure 2) presents three steady states, a decreasing population has either one or two steady states depending on the value of $n$. Thus, an economy with a population growth rate within the interval $\left(-\frac{\delta}{\gamma}, 0\right)$ has two steady states. This economy cannot reach the golden rule equilibrium. On the other hand, if the population growth rate is lower than $-\frac{\delta}{\gamma}$, this economy will only have one steady state. In this particular case, the modified golden rule condition is not attainable.

Figure 2. The Dynamic of Consumption per Capita for an Annuitized Economy with Perfect Foresight Agents. Case $n, \delta>0$ and $\gamma>1$

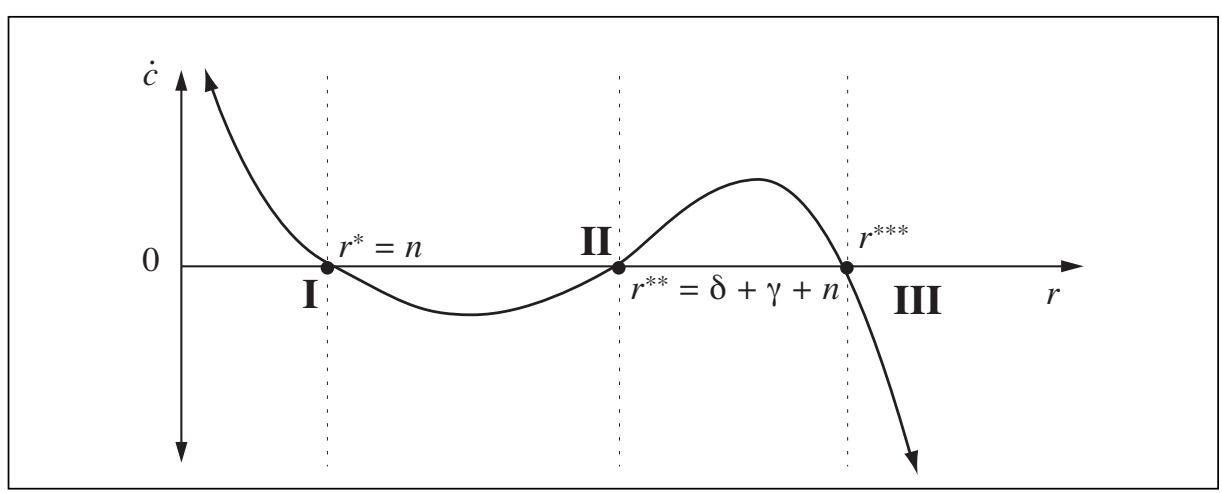

Analyzing the phase diagram and the eigenvalues associated with each point, I can study whether each steady state is an attractor point or not. Note that our dynamic system is not linear; thus I will proceed by linearizing equations (15) and (17) in the neighborhood of each steady state which satisfies Theorem 1 . The linearization gives.

${ }^{9}$ Where the partial derivative of $\phi_{c} \dot{c}$ with respect to $k$ in the neighborhood of $\left(k^{*}, c^{*}\right)$ is

$$
\frac{\partial}{\partial k}\left[c(0) b \int_{0}^{T} \mathrm{e}^{\left(\frac{r(k)-\delta}{\gamma} n\right) \mathrm{s}} \mu(s) \Omega(s) d s\right] \mathrm{c}_{*, \mathrm{k}^{*}}
$$




$$
\left(\begin{array}{l}
\dot{k}(t) \\
\dot{c}(t)
\end{array}\right) \approx\left(\begin{array}{cc}
r\left(k^{*}\right)-n & -1 \\
\left.\frac{\partial \phi_{c} \mathrm{c}}{\partial k}\right|_{c^{*}, k^{*}} & \frac{r\left(k^{*}\right)-\delta}{\gamma}-n
\end{array}\right) \cdot\left(\begin{array}{c}
k(t)-k^{*} \\
c(t)-c^{*}
\end{array}\right)
$$

The roots of the characteristic equation associated with this Jacobian matrix are:

$$
\lambda_{1,2}=\left(1+\frac{1}{\gamma}\right) \frac{r\left(k^{*}\right)}{2}-\frac{\delta}{2 \gamma}-\mathrm{n} \pm \sqrt{\left(\left(1-\frac{1}{\gamma}\right) \frac{r\left(k^{*}\right)}{2}+\frac{\delta}{2 \gamma}\right)^{2}+\left.\frac{\partial \phi_{c} \cdot c}{\partial k}\right|_{c^{*}, k^{*}}}
$$

Equation (21) shows that the eigenvalues not only take both positive and negative values, but also complex ones. Looking at Figure 2, we see that the slope of $\dot{c}$ is positive between points I and III, and yet the slope at each point is different. Through some simulations I have found that if the economy has three equilibria, the middle steady state will be a saddle point and the remaining equilibria will be one stable and one unstable focus. Therefore, this economy can present three different paths: i) a spiral sink, ii) a saddle path, and iii) an unstable spiral. Two of the three paths describe oscillated movements. Thus, it is more likely to see economic cycles, even with perfect foresight agents. On the other hand, an economy with two steady states has an unstable focus and a saddle point. This economy will only have one attractor point instead of two. Finally, an economy with a population growth rate lower than $-\frac{\delta}{\gamma}$ has a repeller point.

Figure 3 below shows the phase diagram of an annuitized economy with a growing population and a constant risk aversion coefficient greater than one. According to the population growth rate, there are three steady states (I, II and III). Point I corresponds to the golden rule interest rate, and point II is the modified golden rule interest rate.

Obviously, the steady state that this economy can reach without social security will depend on initial values of consumption and physical capital per capita. It is worth noting that as long as the economy moves towards point I or point III, many economic variables (e.g. the wage, the interest rates, the consumption per capita, and the physical capital per capita) will have an oscillated motion.

After analyzing every feasible steady state, it is clear that whenever the economy reaches a steady state, generally neither the interest rate, nor the salary is modified. This is true except when the steady state is located at point III. However, and although neither factor prices change at either of the steady states, differences among countries may still appear due to demographic factors. For example, I find that both the con- 
sumption and the stock of physical capital per capita are negatively affected by the proportion of retirees. If we analyze two stationary economies with the same population growth but different life expectancies after the date of retirement, then the economy with the greater life expectancy will have a lower consumption and physical capital per capita than the economy with the lower life expectancy. This is because individuals in both economies earn the same wage and have the same interest rate. However, individuals with a greater life expectancy need to consume less in order to spread their consumption over their life-cycle, as Levhari and Mirman (1977) have already pointed out ${ }^{10}$.

Figure 3. The Phase Diagram for an Annuitized Economy with Perfect Foresight Agents. Case: $n, \delta>0$ and $\gamma>1$

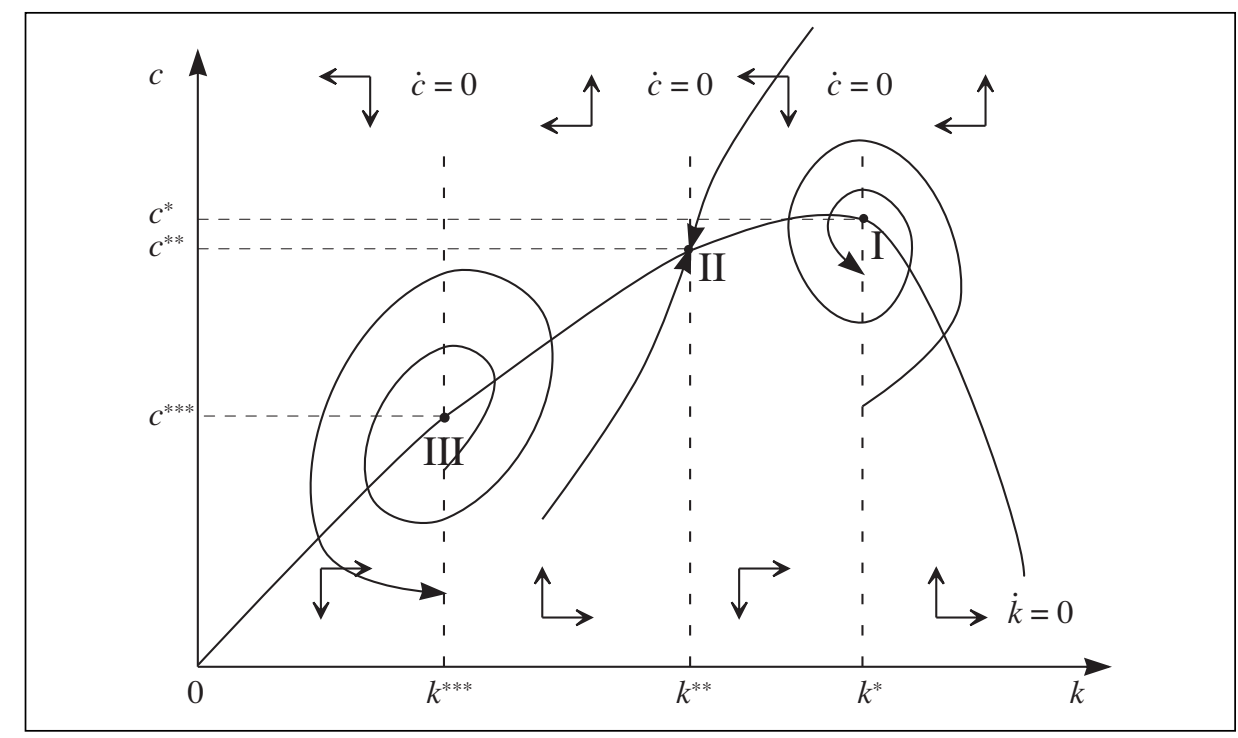

${ }^{10}$ As a consequence, this decrement in consumption can be balanced by either extending the age of retirement, or increasing productivity. 


\section{Impact of Social Security on Economic Growth}

The social security system has been widely criticized because it causes a crowding-out effect on both the stock of physical capital and labor market or, equivalently, because it has a negative impact on individuals' decisions about retirement and saving. These conclusions were made by Feldstein (1974) and Boskin and Hurd (1978), among many others. In addition, the unfunded method of financing Social Security has been identified as the worst method whenever one anticipates an aging population. This demographic scenario undoubtedly yields either a higher payroll tax for workers, reducing their disposable income, or a lower benefit for retirees, or a combination of both. However, there are many other effects that have thus far not been extensively studied in a growth model. For example, how Social Security affects the steady state when realistic demography is taken into account has not been widely addressed. One pioneer work in this field is Bommier and Lee (2003). They find that a closed economy with capital and a social security system is able to reach a steady state that is either «golden rule» or «balanced $»^{11}$. Following the idea of multiple equilibria, I show that both a funded and an unfunded social security can reach a steady state that is either «golden rule,» or «modified golden rule,» when the population increases. Nonetheless, these two social security systems are not completely equivalent even with a stable population, since they approach the steady state following different trajectories. According to this result, under a non-decreasing population the crowding-out effect produced by an unfunded social security does not continue forever, suggesting that it is just a temporary inter-generational problem.

\subsection{Funded Social Security}

To start the analysis I first consider an actuarially fair and funded social security system. In order to focus on the study for the pension system, I leave aside common social security expenditures such as health care, unemployment, etc. Consequently, I assume that Social Security only levies a payroll tax $\tau$ on gross earnings, in exchange

${ }^{11}$ They extended the OLG growth model of Gale (1973) by introducing a productive firm. 
of a future benefit $b$ when people retire. The equation (12) can be rewritten as the following piecewise function:

$$
w_{x}(t-x)=\left\{\begin{array}{clc}
(1-\tau) w(t) & \text { if } & 0<t-x<J \\
b_{x}(t-x) & \text { if } & t-x \geq J
\end{array}\right.
$$

where

$$
b_{x}(t-x)=b=\tau \frac{\int_{0}^{J} w(x+j) \Omega_{x}(j) \mathrm{e}^{-\int_{x}^{x+j} r(p) d p} d j}{\int_{J}^{T} \Omega_{x}(j) \mathrm{e}^{-\int_{x}^{x+j} r(p) d p} d j}
$$

Equation (22) shows that our individual receives a flat pension benefit at retirement. $b$ is actuarially fair, and thus the retiree receives the same return as if she had invested her savings in the private market. However, this fact does not necessarily mean that a funded system is not affected by the population growth rate. According to this framework, the amount of money received through pension benefits will depend on both the interest rate and the survival probability. Thus, if $b$ depends on the interest rate, which is also a function of the population growth rate, then the funded system will be affected by $n$ as well. In order to show this influence and its implications for the economy, we have included Figure 4 below.

In this figure, I present four economic transitions from a golden rule equilibrium to another golden rule for different demographic changes. Thus, it is important to take into account that the time needed to reach the new steady state is in this case longer than if the new steady state was a saddle point («modified golden rule»). I will later compare these results with the analogous case of the unfunded system shown in Figure 5.

First, we should note that a funded social security does not modify the individual allocation process depicted by equations (11) through $(14)^{12}$. Therefore, the steady

12 Given this economic framework, both funded and unfunded social security systems only affect the dynamic of consumption per capita $\dot{c}$ on the initial consumption, $c_{x}(0)$. Using algebra, we can easily prove that under a funded system, the initial consumption does not change. Thus,

$$
c_{x}(0)=\frac{(1-t) \int_{0}^{J} w(x+j) \Omega_{x}(j) \mathrm{e}^{-\int_{x}^{x+j} r(p) d p} d j+b \int_{J}^{T} \Omega_{x}(j) \mathrm{e}^{-\int_{x}^{x+j} r(p) d p} d j}{\int_{0}^{T} \Omega_{x}(j) \mathrm{e}^{-\left(1-\frac{1}{\gamma}\right) \int_{x}^{x+j} r(p) d p} \mathrm{e}^{-\frac{\delta}{\gamma} j} d j} .
$$


Figure 4. Economic Transitions between Two Golden Rule Steady States: Funded Social Security $(\tau=0.08)$

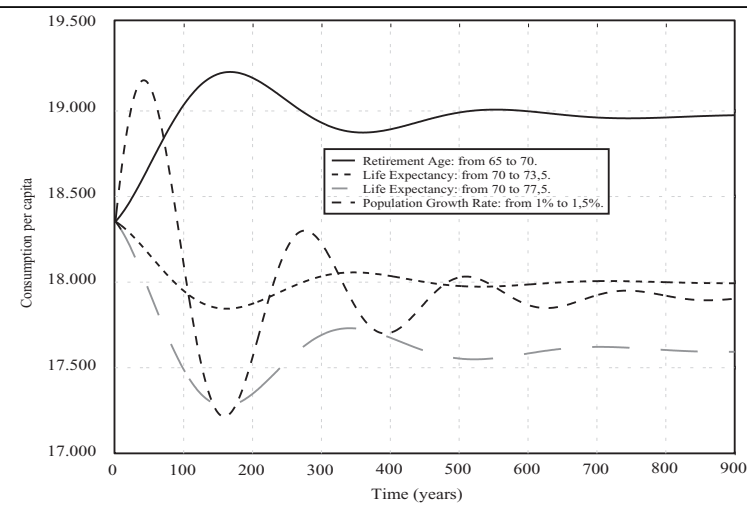

(a) Consumption per capita $\mathrm{c}(\mathrm{t})$

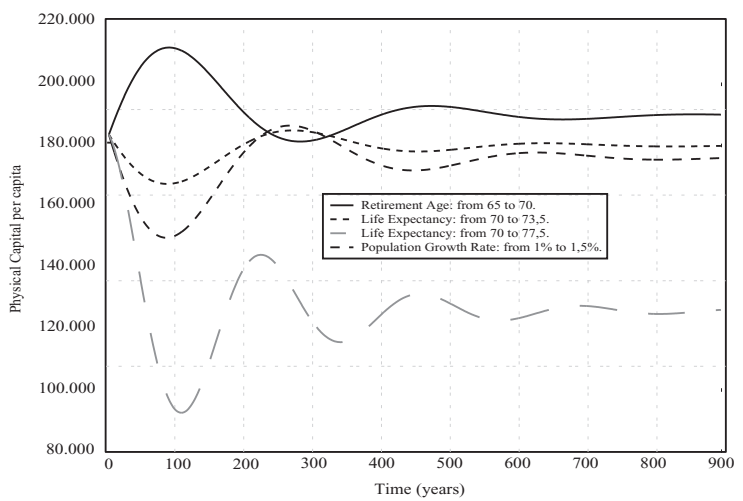

(b) Physical Capital per capita k(t)

Note. This analysis assumes a CES production function $A\left(\theta k^{\alpha}+(1-\theta) l^{\alpha}\right)^{\frac{1}{\alpha}}$, where the parameters used are $\{A=2093, \theta=1 / 3, \alpha=-0.131855\}, T=120, \delta=0.01$, and $\gamma=1$. The other parameters are reported in the figure.

Note that if we substitute $b$ into equation (22), the initial consumption will be the same as in the case of not having a social security. That is,

$$
c_{x}(0)=\frac{\int_{0}^{J} w(x+j) \Omega_{x}(j) \mathrm{e}^{-\int_{x}^{x+j} r(p) d p} d j}{\int_{0}^{T} \Omega_{x}(j) \mathrm{e}^{-\left(1-\frac{1}{\gamma}\right) \int_{x}^{x+j} r(p) d p} \mathrm{e}^{-\frac{\delta}{\gamma} j} d j} .
$$


states of this economy are the same as those steady states obtained in the benchmark economy explained in Section 4. Secondly, I have chosen the golden rule equilibrium in this figure because, on the one hand, it is the steady state in which the population maximizes its welfare, and, on the other hand, it is an attractor point which makes future comparisons easier ${ }^{13}$.

Figure 4 shows that an economy with a funded social security is negatively affected by an increase in both the life expectancy at birth (dotted line, and dotted-dashed line) and the population growth rate (dashed line). In contrast, delaying the mandatory age of retirement from 65 years old to 70 years old raises both consumption and physical capital per capita. Therefore, the latter policy seems to be the most convenient in the case of a growing population with an increasing life expectancy. We can also observe from Figure 4 that a funded system contains cyclical movements, since the number of cycles depends on the number of oscillations. On the other hand, and contrary to the unfunded system, these economic transitions are independent of the payroll tax levied, even though both consumption and physical capital per capita are modified at an individual level. This circumstance plays an important role in the next subsection through the number of oscillations.

\subsection{Unfunded Social Security}

Under an unfunded social security system, current workers support the pension benefits received by retirees, redistributing income over multiple generations. The pension benefits at time $t$ are in this case:

$$
b_{x}(t-x)=\tau_{w}(t) \frac{\int_{t-J}^{t} p_{x}(t-x) d x}{\int_{t-T}^{t-T} p_{x}(t-x) d x}=\tau_{w}(t) \frac{l(t)}{1-l(t)} .
$$

This pension benefit is a function of both the population structure through $l(t)$ and the current economic status through $w(t)$. Consequently, an unfunded social security system is more affected than a funded system by the population structure at any time. Now, comparing the pension benefit received from a pure funded social security, see

${ }^{13}$ Unfortunately, the time it takes to reach another steady state is too long for a stable population. By contrast, an economy with a demographic transition has faster movements. 
equation (22), with that of an unfunded social security, we can observe under steady state conditions that the following relationship is satisfied:

$$
\left\{\begin{array}{cl}
\tau w \frac{l}{1-l}<\tau w \frac{\int_{0}^{J} \mathrm{e}^{-r s} \Omega(s) d s}{\int_{J}^{T} \mathrm{e}^{-r s} \Omega(s) d s} & \text { if } r>n \\
\tau w \frac{l}{1-l}>\tau w \frac{\int_{0}^{J} \mathrm{e}^{-r s} \Omega(s) d s}{\int_{J}^{T} \mathrm{e}^{-r s} \Omega(s) d s} & \text { if } r<n
\end{array}\right.
$$

The importance of this relationship for the analysis is twofold. One, it helps to give insight into which system yields a greater pension benefit for a given payroll tax $\tau$. Thus, once the steady state is known, we can specify which social security system yields a greater welfare. Second, because an unfunded social security does not offer the same return as private markets, initial consumption is not the same as that in a funded system. Therefore, we may wonder whether an unfunded system affects the steady states that this economy reaches.

It is easy to see from Theorem 1 that the modified golden rule is independent of the type of social security system that an economy has. However, equation (17) is not the same due to the initial consumption. In particular, $c(0)$ now has the following expression

$$
\frac{(1-\tau) w \int_{0}^{T} \Omega(s) \mathrm{e}^{-r s} d s+\tau w \frac{1}{1-l} \int_{J}^{T} \Omega(s) \mathrm{e}^{-r s} d s}{\int_{0}^{T} \mathrm{e}^{-\left(\left(1-\frac{1}{\gamma}\right) r+\frac{\delta}{\gamma}\right) s} \Omega(s) d s}
$$

Equation (25) shows that with regard to (24), $c(0)$ is greater (respectively lower) under an unfunded system than $c(0)$ under a funded system whenever $r<$ (respectively $>$ ) $n$. Therefore, I can claim that an unfunded social security leaves the population better (respectively worse) off whenever a stationary economy has an interest rate lower (respectively greater) than the population growth rate. Following this reasoning, I find that

Proposition 1. Under the golden rule equilibrium both funded and unfunded social security systems yield the same welfare for every cohort.

Proof. See Appendix. 
Thus, if the economy is in the golden rule equilibrium, there will be no interest in switching from one social security system to another ${ }^{14}$. That is, every individual will have the same consumption trajectory under both social security systems. In addition to Proposition 1, we also find that

Proposition 2. Both funded and unfunded social security systems can reach either the modified golden rule or the golden rule equilibrium.

The proof is obvious from the observation of Theorem 1 and Proposition 1.

Theorem 1 gives three steady states for a growing population. In fact, it is not included in Proposition 2 because both systems do not attain the same non-trivial steady states shown in Figure 3. On the other hand, it is important to note that as long as $r=\delta+\gamma n$ is lower than $n$, an unfunded system will be more desirable than a funded system, and vice versa. Therefore, the risk aversion coefficient $\gamma$ and the subjective discount factor $\delta$ seem to be crucial variables for determining the optimal social security system under this model.

According to Proposition 2, the non-trivial steady state is the only steady state point that changes. However, it is not the optimal steady state, since it does not maximize the aggregate consumption as the golden rule does. Given this circumstance, we will henceforth focus on the golden rule equilibrium.

I have pointed out that an unfunded social security modifies the dynamic of consumption per capita. Thus, the eigenvalues reported in equation (21) differ from the funded system eigenvalues because of the function $\left.\frac{\partial \phi_{c} c}{\partial k}\right|_{k^{*}, c^{*}}$. If I consider that the golden rule is a spiral sink, we can be sure that the speed of convergence from an initial state $\left(k_{0}, c_{0}\right)$ to the steady state $\left(k^{*}, c^{*}\right)$ is the same for both systems. In other words, in both systems the real point of the eigenvalues $\operatorname{Re}(\lambda)$ is equal. However, the imaginary part of the eigenvalues $\operatorname{Im}(\lambda)$ for both systems are not equal. As a consequence, an unfunded system moves towards the equilibrium with a different trajectory than a funded system. Figure 5 shows the economic transitions from a golden rule equilibrium to another under the same demographic changes introduced in Figure 4.

${ }^{14}$ Of course, the population growth rate should be positive due to the impossibility that the interest rate will be negative. 
Figure 5. Economic Transitions between Two Golden Rule Steady States: Unfunded Social Security $(\tau=0.08)$

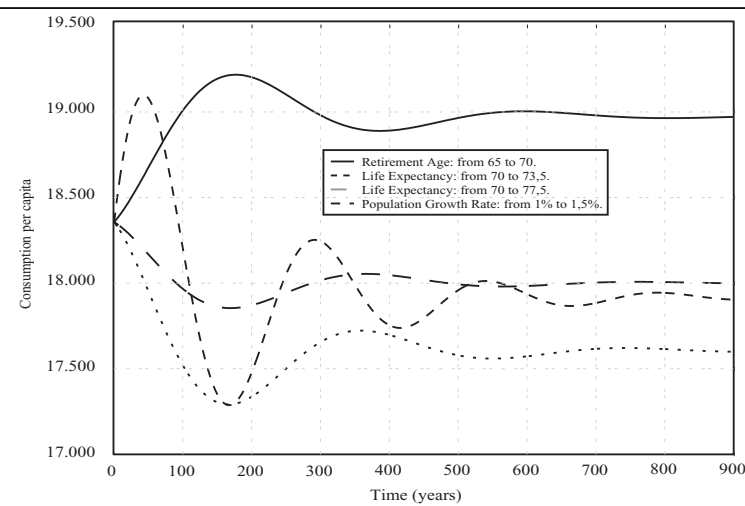

(a) Consumption per capita $\mathrm{c}(\mathrm{t})$

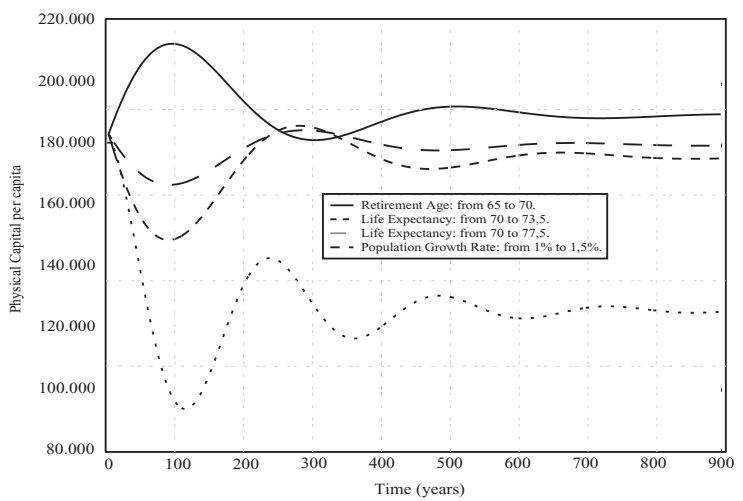

(b) Physical Capital per capita k(t)

Note. This analysis assumes a CES production function $A\left(\theta k^{\alpha}+(1-\theta) l^{\alpha}\right)^{\frac{1}{\alpha}}$, where the parameters used are $\{A=2093, \theta=1 / 3, \alpha=-0.131855\}, T=120, \delta=0.01$, and $\gamma=1$. The other parameters are reported in the figure.

Looking at Figures 4 and 5 we can see how both systems reach the same steady states, despite the fact that the economic trajectories vary between social security systems. In particular, an unfunded system has a smaller imaginary part $\operatorname{Im}(\lambda)$ than a funded system. As a consequence, the number of oscillations diminishes as the payroll tax raises. Furthermore, an important finding shown in Figure 5 is that a lower population growth rate affects a funded system more heavily than an unfunded system. Therefore, given a demographic change of $n>0$, the economic transition 
between two golden rule equilibria is a temporary intergenerational problem, which is better off under an unfunded system only at the beginning of the transition.

\section{Conclusions}

This paper shows that both the introduction of realistic demography and a longitudinal accounting has very important effects on economic growth models. Under a Cass-Koopmans-Ramsey model, I find that multiple steady states exist. For example, for a positive population growth rate, there exist three steady states: i) golden rule, ii) modified golden-rule, and iii) a non-trivial equilibrium which depends on both economic and demographic variables. I also find that the number of steady states is an increasing function of the population growth rate, which goes from a minimum of one to a maximum of three. Further, the equilibrium paths cannot only be a saddle path, but also a spiral sink and an unstable spiral. Therefore, this model leads to cyclical movements even with perfect foresight agents.

Afterwards, I have used the model to study the impact of social security on economic growth. I find that both funded and unfunded social security systems can achieve either the modified golden-rule or the golden rule equilibrium. However, only under the golden rule equilibrium do both systems yield the same welfare for every individual. This first result suggests that social security does not crowd out the stock of physical capital in the long run, although it does before the economy reaches the steady state. Second, whether an unfunded system is preferable to a funded system depends on many demographic and economic variables that must be further researched. 


\section{ApPENDix}

Definition 2 Let $\Omega \in C^{2}([0, T))$ denote the rational discount function, i.e. the probability that the consumer will be alive at age s. $\Omega$ has the following properties:

1. $\Omega(0)=1$.

2. $\lim _{s \rightarrow T} \Omega(s)=0$.

3. $0<\Omega(s) \leq 1$.

4. $\Omega(\tau)<\Omega(s) \Leftrightarrow \tau>s$.

5. $-\frac{\frac{d}{d s} \Omega(s)}{\Omega(\mathrm{s})}=\mu(s)>0$.

where $\mu \in C^{\infty}([0, T))$ is the instantaneous mortality rate.

6. The mortality hazard rate $\mu$ is an increasing function of age ${ }^{15}$.

$$
\frac{d}{d s} \mu(s) \geq 0, \forall s \in[0, T) \text {. }
$$

7. In particular, the probability of being alive at age $x$ is given by the following mapping:

$$
\begin{aligned}
\Omega:[0, T) & \rightarrow(0,1] \\
s & \rightarrow \Omega(s)=\mathrm{e}^{\int_{0}^{s} \mu(\tau) d \tau}
\end{aligned}
$$

Proof of Theorem 1. In order to prove Theorem 1, we will proceed in two steps. First, we will derive the two necessary conditions for a steady state economy. Second, we will show how the golden rule interest rate also satisfies this theorem.

${ }^{15}$ In general, this is not true at young ages, although it is assumed for the sake of simplicity. 
We use the cross-sectional accounting framework because we have assumed that the population is stable. By hypothesis, the optimal consumption of any individual at age $s$ can be depicted by

$$
c(s)=c(0) \mathrm{e}^{\frac{r-\delta}{\gamma}}, \forall s \in[0, T) .
$$

Thus, by plugging the consumption trajectory into equation (17), the dynamic of consumption per capita is

$$
\dot{c}=\left(\frac{r-\delta}{\gamma}-n\right) c+c(0) b\left(1-\int_{0}^{T} \mathrm{e}^{\left(\frac{r-\delta}{\gamma} n\right) s} \mu(s) \Omega(s) d s\right)
$$

Using Definition 2 and Property 5 , we know that $-\mu(s) \Omega(s)$ can be replaced by $\frac{d \Omega(s)}{d s}$. Now, recalling $u$ as $\mathrm{e}^{\left(\frac{r-\delta}{\gamma}-n\right) s}$ and $d v$ as $d \Omega(s)$, and applying the rule $\left.u \cdot v\right|_{0} ^{T}-\int_{0}^{T} v \cdot d u$, we get

$$
\dot{c}=\left(\frac{r-\delta}{\gamma}-n\right)\left(c-c(0) b \int_{0}^{T} \mathrm{e}^{\left(\frac{r-\delta}{\gamma}-n\right) s} \Omega(s) d s\right) .
$$

A steady state economy should assure that $\dot{k}=0 \Leftrightarrow c=f-n k$. Furthermore, given that $f$ is a homogeneous function of degree one, we know that the latter condition can be rewritten as $c=(r-n) k+w l$. Therefore, a necessary condition for a steady state economy must guarantee that both $c=0$ and $\dot{k}=0$, or equivalently:

$$
r=\delta+\gamma n
$$

or,

$$
(r-n) k+w l=c(0) b \int_{0}^{T} \mathrm{e}^{\left(\frac{r-\delta}{\gamma}-n\right) s} \Omega(s) d s .
$$

Up to this point we have proven that an economy with an interest rate that satisfies either equation (18) or (19) is under a steady state. From equation (18) we immediately know that one interest rate follows the modified golden rule. However, we have not yet specified what interest rates are contained in equation (19). In order to show that the golden rule is a possibility, we first need to evaluate the initial consumption. Thus, 


$$
c(0)=\frac{w \int_{0}^{J} \Omega(s) \mathrm{e}^{-r s} d s}{\int_{0}^{T} \mathrm{e}^{-\left(\left(1-\frac{1}{\gamma}\right) r+\frac{\delta}{\gamma}\right) s} \Omega(s) d s} .
$$

Plugging the initial consumption into the equation (19), we find that

$$
(r-n) k+w l=\frac{w \int_{0}^{J} \Omega(s) b \mathrm{e}^{-r s} d s \int_{0}^{T} \mathrm{e}^{\left(\frac{r-\delta}{\gamma}-n\right) s} \Omega(s) d s}{\int_{0}^{T} \mathrm{e}^{-\left(\left(1-\frac{1}{\gamma}\right) r+\frac{\delta}{\gamma}\right) s} \Omega(s) d s} .
$$

The substitution of $r$ by the golden rule condition $n$ gives the following relationship:

$$
l=\int_{0}^{J} \Omega(s) b \mathrm{e}^{-r s} d s
$$

which is exactly the proportion of workers per capita under a stable population. Therefore, $r=n$ satisfies the equation (19).

Proof of Proposition 1. Given that private markets offer actuarially fair annuities and the population structure is stable over time, we only need to demonstrate that the initial consumption under both systems is the same whenever $r=n$. Thus, recalling equation (25)

$$
c(0)=\frac{(1-\tau) w \int_{0}^{J} \Omega(s) \mathrm{e}^{-r s} d s+\tau w \frac{1}{1-l} \int_{J}^{T} \Omega(s) \mathrm{e}^{-r s} d s}{\int_{0}^{T} \mathrm{e}^{-\left(\left(1-\frac{1}{\gamma}\right) r+\frac{\delta}{\gamma}\right) s} \Omega(s) d s}
$$

and rearranging its numerator, gives

$$
c(0)=\frac{w \int_{0}^{J} \Omega(s) \mathrm{e}^{-r s} d s+\tau w\left(\frac{1}{1-l} \int_{J}^{T} \Omega(s) \mathrm{e}^{-r s} d s-\int_{0}^{J} \Omega(s) \mathrm{e}^{-r s} d s\right)}{\int_{0}^{T} \mathrm{e}^{-\left(\left(1-\frac{1}{\gamma}\right) r+\frac{\delta}{\gamma}\right) s} \Omega(s) d s}
$$

Multiplying and dividing by $b$ in the parenthesis located in the numerator, we have that 


$$
c(0)=\frac{w \int_{0}^{J} \Omega(s) \mathrm{e}^{-r s} d s+\frac{\tau w}{b}\left(\frac{1}{1-l} \int_{J}^{T} \Omega(s) \mathrm{e}^{-r s} d s-\int_{0}^{J} \Omega(s) \mathrm{e}^{-r s} d s\right)}{\int_{0}^{T} \mathrm{e}^{-\left(\left(1-\frac{1}{\gamma}\right) r+\frac{\delta}{\gamma}\right) s} \Omega(s) d s}
$$

Now, substituting $r$ by $n$, and using equations (4), and (10), we obtain that

$$
c(0)=\frac{w \int_{0}^{J} \Omega(s) \mathrm{e}^{-n s} d s}{\int_{0}^{T} \mathrm{e}^{-\left(\left(1-\frac{1}{\gamma}\right) n+\frac{\delta}{\gamma}\right) s} \Omega(s) d s}
$$

This result is the same as the initial consumption of a funded social security.

\section{REFERENCES}

Aвel, A. B. (1985). «Precautionary Saving and Accidental Bequest». The American Economic Review 75(4), 777-791.

Auerbach, A. J. and L. J. Kotlikoff (1987). Dynamic Fiscal Policy. New York: Cambridge University Press.

Blanchard, O. J. (1985). «Debt, Deficits, and Finite Horizons». The Journal of Political Economy 93(2), 223-247.

Bommier, A. and R. D. Lee (2003). «Overlapping Generations Models with Realistic Demography». Journal of Population Economics 16, 135-160.

Boskin, M. and M. Hurd (1978). «The Effect of Social Security on Early Retirement». Journal of Public Economics 10(3), 361-377.

Calvo, G. A. and M. Obstreld (1988). «Optimal Time-Consistent Fiscal Policy with Finite Lifetimes». Econometrica 56(2), 411-432.

CAss, D. (1965). «Optimum Growth in an Aggregate Model of Capital Accumulation». Review of Economic Studies 32, 233-240.

Feldstein, M. (1974). «Social Security, Induced Retirement, and Aggregate Capital Accumulation». Journal of Political Economy 82(5), 905-926.

Fuster, L. (1999). «Is Altruism Important for Understanding the Long-Run Effects of Social Security?». Review of Economic Dynamics 2, 616-637.

Fuster, L., A. Imrohoroğlu, and S. Imrohoroğlu (2003). «A Welfare Analysis of Social Security in a Dynastic Framework». International Economic Review 44(4), 1247-1274.

GaLE, D. (1973). «Pure Exchange Equilibrium of Dynamic Economic Models». Journal of Economic Theory 6, 12-36.

Hubbard, R. G. (1987). Issues in Pension Economics, Chapter Uncertain Lifetime, Pensions, and Individual Saving, pp. 175-206. NBER. 
Koopmans, T. C. (1965). The Economic Approach to Development Planning, Chapter «On the Concept of Optimal Economic Growth». Amsterdam: North-Holland.

Levhari, D. and L. J. Mirman (1977). «Saving and Consumption with an Uncertain Horizon». The Journal of Political Economy 85(2), 265-281.

Phelps, E. S. (1966). Golden Rules of Economic Growth. New York: Norton.

Ramsey, F. (1928). «A Mathematical Theory of Saving». The Economic Journal 38(152), $543-559$.

Solow, R. M. (1956). «AContribution to the Theory of Economic Growth». The Quarterly Journal of Economics 70(1), 65-94.

YAARI, M. (1965). «Uncertain Lifetime, Life Insurance, and the Theory of the Consumer». The Review of the Economic Studies 5(3), 304-317. 
